\title{
Effects of a Chimeric Lysin against Planktonic and Sessile Enterococcus faecalis Hint at Potential Application in Endodontic Therapy
}

\author{
Wuyou Li ${ }^{1,+}$, Hang Yang ${ }^{2, *}+\underset{1}{ }$, Yujing Gong ${ }^{3}$, Shujuan Wang ${ }^{2}$, Yuhong $\mathrm{Li}^{1, *}$ and \\ Hongping Wei ${ }^{2, *}$ \\ 1 The State Key Laboratory Breeding Base of Basic Science of Stomatology (Hubei-MOST) \& Key \\ Laboratory of Oral Biomedicine, Ministry of Education, School of Stomatology, Wuhan University, \\ Wuhan 430079, China; 2016203040006@whu.edu.cn \\ 2 Key Laboratory of Special Pathogens and Biosafety, Center for Emerging Infectious Diseases, \\ Wuhan Institute of Virology, Chinese Academy of Sciences, Wuhan 430071, China; wangsj@wh.iov.cn \\ 3 State Key Laboratory of Agricultural Microbiology, College of Life Science and Technology, \\ Huazhong Agricultural University, Wuhan 430070, China; hejin@mail.hzau.edu.cn \\ * Correspondence: yangh@wh.iov.cn (H.Y.); 1004809372@whu.edu.cn (Y.L.); hpwei@wh.iov.cn (H.W.); \\ Tel.: +86-27-5186-1078 (H.Y.); +86-27-8764-7443 (Y.L.); +86-27-5186-1076 (H.W.); Fax: +86-27-8719-9492 (H.Y.); \\ +86-27-8764-7443 (Y.L.); +86-27-8719-9492 (H.W.) \\ + These authors contributed equally to this work.
}

Received: 29 April 2018; Accepted: 23 May 2018; Published: 29 May 2018

\begin{abstract}
Enterococcus faecalis is a commensal opportunistic pathogen found in the intestine, mouth, and vaginal tract of humans. As an invasive pathogen in the oral cavity, E. faecalis is one of the leading causes of periapical endodontic lesions. However, due to the strong biofilm-forming capacity and tolerance of E. faecalis to conventional antibiotics and treatments, limited therapeutic options are available. In the present study, we investigated the activity of ClyR, a chimeric lysin with extended streptococcal lytic spectrum, against planktonic and sessile E. faecalis cells in vitro and in an ex vivo dental model. Our results showed that $\mathrm{ClyR}$ has robust and rapid lytic activity against multiple E. faecalis strains, killing $>90 \%$ planktonic cells within $1 \mathrm{~min}$ at a concentration of $50 \mu \mathrm{g} / \mathrm{mL}$. The biochemical experiments combined with microscopy analysis revealed that $\mathrm{ClyR}$ degrades E. faecalis biofilm with high efficacy in a dose-dependent manner, reducing the survival rate to $<40 \%$ within biofilms after treatment with $50 \mu \mathrm{g} / \mathrm{mL}$ ClyR for $1 \mathrm{~h}$. In the ex vivo dental model, ClyR showed a significant biofilm removal efficacy, killing $>90 \%$ viable bacteria within biofilms at a low dose of $50 \mu \mathrm{g} / \mathrm{mL}$, which is much better than ampicillin and similar to calcium hydroxide, the extensively used routine intracanal medicament in the treatment of endodontics and dental traumatology. The robust activity of ClyR against both planktonic and sessile E. faecalis suggests the potential of ClyR in treating endodontic infections caused by E. faecalis.
\end{abstract}

Keywords: bacteriophage lysin; Enterococcus faecalis; bacterial biofilm; endodontic infection; calcium hydroxide

\section{Introduction}

Enterococcus faecalis, an opportunistic Gram-positive pathogen, is a member of the normal microorganisms of the oral cavity, intestines, and vaginal tract of human beings and animals [1]. As a common community of oral microbiota, E. faecalis has found to be involved in the microflora of the root canal and the periodontal pocket that do not respond well to conventional root canal therapy [2]. In most instances, E. faecalis can survive as biofilm in the surface of the dentinal tubule or 
within granules combined with other anaerobic and facultative bacteria, making refractory periapical endodontic lesions difficult to cure [3,4]. Because of the strong biofilm formation ability, which empowers bacteria enhanced resistance to antimicrobial agents $[5,6]$, attenuated susceptibility to host immune clearance and phagocytosis $[7,8]$, and the increased emergence of multidrug resistance isolates [9,10], E. faecalis now represents a great challenge to public health worldwide [11,12]. Therefore, alternatives effective against $E$. faecalis and its biofilm are urgently needed.

In recent years, lysin therapy has attracted much attention because of the highly efficient bactericidal activity in vitro and in animal infection models [13-15]. Lysins encoded by bacteriophages can cause a time-clocked cell lysis from within, and can also result in rapid cell wall degradation against a susceptible Gram-positive bacterium when added exogenously [16,17]. Due to their robust cell lysis capacity, lysins have also been found capable of degrading bacterial biofilms through a layer-by-layer model, for instance, $\mathrm{PlyC}$ is highly active against Streptococcus pyogenes biofilm [15], several staphylococcal lysins (such as CF-301 [18], ClyH [19], ClyF [20], phi11 endolysin [21], SAL-2 [22], Ply187AN-KSH3b [23], P128 [24] and so on) have reported to be active against Staphylococcus aureus biofilm in vitro and in skin infection models, lysin LySMP is capable of removing Streptococcus suis biofilm [25], pneumococcal lysins Cpl-1 and Cpl-7 are efficient against Streptococcus pneumoniae biofilm [26], and ClyR has reported to be the first lysin that is active against Streptococcus mutans biofilm [27]. Few lysins with significant bactericidal activity against $E$. faecalis have been developed to date, including the chimeric lysin ClyR that comprises the CHAP domain of PlyC lysin and the cell-wall binding domain of PlySs2 lysin and shows extended streptococcal lytic spectrum [28], the natural lysin LysEF-P10 [29], and the chimeric lysin EC300 [30]. However, as far as we know, no study has been done on using lysins to treat biofilms of E. faecalis in dental models.

In the present study, we tested the bactericidal activity of ClyR against planktonic and sessile E. faecalis in vitro and in an ex vivo dental model.

\section{Materials and Methods}

\subsection{Bacterial Strains and Protein}

All E. faecalis strains used in this study were routinely grown in brain heart infusion (BHI) broth at $37^{\circ} \mathrm{C}$, and $3 \%$ glucose was added in biofilm cultivation. A collection of clinical E. faecalis isolates were obtained from different patients and provided by Wuhan University Stomatological Hospital and identified by PCR-DNA sequencing analysis combined with biochemistry test using a MicroStation system (Biolog, GENIII Omnilog Combo Plus System, Hayward, CA, USA). The chimeric lysin, ClyR, was expressed in E. coli BL21(DE3), purified through Ni-nitrilotriacetic acid affinity chromatography and dialyzed against phosphate-buffered saline (PBS, containing $137 \mathrm{mM} \mathrm{NaCl}, 2.7 \mathrm{mM} \mathrm{KCl}, 10 \mathrm{mM}$ $\mathrm{Na}_{2} \mathrm{HPO}_{4}, 2 \mathrm{mM} \mathrm{KH}{ }_{2} \mathrm{PO}_{4}, \mathrm{pH}$ 7.4) as described previously [28].

\subsection{In Vitro Lytic Activity Assay}

Bacterial cells were cultured overnight, centrifuged, and re-suspended in PBS to a final $\mathrm{OD}_{600}$ of 0.8-1.0 ( 108 colony-forming unit (CFU)/mL). Then $160 \mu \mathrm{L}$ of each bacterial suspension was mixed with $40 \mu \mathrm{L}$ ClyR (to a final concentration of $12.5,25,50$, or $100 \mu \mathrm{g} / \mathrm{mL}$ ) in a 96-well plate (Perkin-Elmer, Shanghai, China), the drop of $\mathrm{OD}_{600}$ in each well was monitored simultaneously by a microplate reader (Synergy H1, BioTek, Winooski, VT, USA) at $37^{\circ} \mathrm{C}$ for $30 \mathrm{~min}$.

To test the time- and dose-dependent killing capacity of ClyR, E. faecalis ATCC 51299 cells were treated either with different concentrations of ClyR $(0,0.5,2,5$, and $25 \mu \mathrm{g} / \mathrm{mL})$ for $40 \mathrm{~min}$ at $37^{\circ} \mathrm{C}$, or treated with $50 \mu \mathrm{g} / \mathrm{mL}$ ClyR for different times $(0,0.5,1,5$, and $15 \mathrm{~min})$ at $37^{\circ} \mathrm{C}$, after that, viable cell numbers after each treatment were determined by serial ten-fold dilution and plating on BHI agar. All experiments were repeated for at least three replicates. 


\subsection{MIC Determination}

The MIC (minimal inhibitory concentration) of several antibiotics (vancomycin, ampicillin, daptomycin, and erythromycin) against E. faecalis ATCC 51299 was performed as described [31], with minor modifications. Briefly, overnight cultures of $E$. faecalis were centrifuged and re-suspended in PBS to an $\mathrm{OD}_{600}$ of 0.7. After dilution 10-fold with fresh cation-adjusted Mueller-Hinton broth (CAMHB) medium, $10 \mu \mathrm{L}$ of the bacterial dilution was added to a 96-well polystyrene tissue culture plate pre-supplemented with CAMHB containing various concentrations of antibiotics (a total volume of $200 \mu \mathrm{L}$ ) and incubated statically for $24 \mathrm{~h}$ at $37^{\circ} \mathrm{C}$. MIC was defined as the lowest concentration of antibiotic that inhibits visible growth.

\subsection{In Vitro Biofilm Grown Condition and Detection Assay}

E. faecalis biofilm was cultured in BHI supplemented with 3\% glucose (BHIG) according to the method described [32], with minor modifications. Briefly, overnight cultures of E. faecalis ATCC 51299 were centrifuged and re-suspended in PBS to a final $\mathrm{OD}_{600}$ of $0.7\left(\sim 10^{8} \mathrm{CFU} / \mathrm{mL}\right)$. An amount of $10 \mu \mathrm{L}$ of bacterial suspension was mixed with $190 \mu \mathrm{L}$ BHIG in a 96-well polystyrene plate (Tissue culture treated, Nest Biotech Co., Wuxi, Jiangsu, China) and incubated for $24 \mathrm{~h}$ at $37^{\circ} \mathrm{C}$ to allow biofilm formation. After removing the planktonic phase and washing three times with PBS, biofilms were treated with $200 \mu \mathrm{L}$ different concentrations of ClyR $(0,50,100$, and $200 \mu \mathrm{g} / \mathrm{mL})$ for $1 \mathrm{~h}$ at $37^{\circ} \mathrm{C}$. Washing twice with PBS to remove the residual amount of antimicrobials, biofilms were fixed by $100 \mu \mathrm{L}$ methyl alcohol for $15 \mathrm{~min}$. Then, the adhered biofilms were stained with $50 \mu \mathrm{L}$ of $0.1 \%(w / v)$ crystal violet at room temperature for $5 \mathrm{~min}$. Finally, wells were washed with flowing water and solubilized with $200 \mu \mathrm{L}$ ethanol to detect the absorbance at $595 \mathrm{~nm}$. Meanwhile, in order to determine the viable cell number within each well after antimicrobial treatment, cells were recovered by adding $100 \mu \mathrm{L}$ PBS and scratching with a sterile swab. After ultrasonication for $2 \mathrm{~min}$ (to fully disaggregate biofilm), samples were series diluted and plated to BHI agar.

\subsection{Dentin Slices Preparation and Biofilm Cultivation}

The caries-free single-rooted teeth used in this study were selected from orthodontic extraction approved by the ethics committee of Wuhan University (No. 2016-30, 26 February 2016). The teeth were soaked in $0.01 \% \mathrm{NaClO}$ solution for 6 days, shaped to a size of $4 \times 4 \times 2 \mathrm{~mm}$ semicylindrical dentin slice, and ultrasoniced for 4 min respectively with $5.25 \% \mathrm{NaClO}$ and $6 \%$ citric acid (Sigma, Shanghai, China) at 40,000 Hz by an ultrasonic bath (SB-5200 DTD, SCIENTZ, Ningbo, China) to remove the smear layer on both sides of the specimen. Finally, all dentin slices were washed with sterile water and sterilized for $20 \mathrm{~min}$ at $121^{\circ} \mathrm{C}$. E. faecalis ATCC 51299 was cultured in BHIG in 24-well plates containing one dentin slice for $24 \mathrm{~h}$ to allow biofilm formation. After washing twice with PBS, the dentin slice was transferred to a sterilized tube and treated with either $50 \mu \mathrm{g} / \mathrm{mL}$ ClyR, $50 \mathrm{mg} / \mathrm{mL}$ ampicillin, or $0.5 \%$ calcium hydroxide $\left(\mathrm{Ca}(\mathrm{OH})_{2}\right)$ for $1 \mathrm{~h}$ at $37^{\circ} \mathrm{C}$. Washed twice with PBS, dentin slices were ultrasoniced $2 \mathrm{~min}$ in PBS (to fully disaggregate biofilm), and series diluted for checking viable cell numbers on BHI agar.

\subsection{Transmission Electron Microscopy}

Overnight cultures of E. faecalis ATCC 51299 cells were washed with PBS and treated with different concentrations of ClyR $(0,50,100$, and $200 \mu \mathrm{g} / \mathrm{mL})$ for $1 \mathrm{~h}$ at $37^{\circ} \mathrm{C}$. After adding glutaraldehyde to a final concentration of $2.5 \%$, bacterial suspension was sampled and analyzed by using a transmission electron microscope (Tecnai $\mathrm{G}^{2} 20$ Twin; Fei, Hillsboro, OR, USA).

\subsection{Scanning Electron Microscopy}

In order to visualize the structural changes of E. faecalis biofilms after exposure to ClyR, E. faecalis ATCC 51299 biofilms grown on glass coverslips for $24 \mathrm{~h}$ were washed twice with PBS (to remove the 
planktonic cells), and treated with $50 \mu \mathrm{g} / \mathrm{mL}$ ClyR for $1 \mathrm{~h}$. Biofilms were then washed twice with PBS, fixed with $2.5 \%$ glutaraldehyde overnight at $4{ }^{\circ} \mathrm{C}$, dehydrated by granted ethanol (from $30 \%$ to $100 \%$ ), and analyzed by a SU8010 scanning electron microscope (SEM, Hitachi, Tokyo, Japan). The PBS treated groups were used as controls. Images were taken at $\times 20,000$ magnification under the same instrument conditions.

\subsection{Confocal Laser Scanning Microscopy}

E. faecalis biofilms cultured in glass bottom dish (NEST) for $24 \mathrm{~h}$ were treated with various concentrations of ClyR $(0,100$, and $200 \mu \mathrm{g} / \mathrm{mL})$, washed twice with PBS, and stained with LIVE/DEAD BacLight bacterial viability kit (L7010, Invitrogen, Carlsbad, CA, USA) for $15 \mathrm{~min}$ at room temperature. Finally, biofilms were washed by distilled water, and imaged by using an UltraVIEW VoX confocal laser scanning microscope (CLSM, PerkinElmer, Waltham, MA, USA). All acquired images were analyzed by the Volocity (version 6.3.0, PerkinElmer, Waltham, MA, USA) software supplied with the instrument.

\section{Results}

\subsection{ClyR Is Highly Active against Multiple Planktonic E. faecalis}

In previous studies, we have confirmed that ClyR is active against one E. faecalis strain [28]. Herein, we examined the bacteriocidal activity of ClyR against $E$. faecalis in detail using more different isolates. As shown in Figure 1a, ClyR caused a rapid decrease in turbidity of E. faecalis in a dose-dependent manner, with a reduction from $0.6\left(\sim 1.36 \times 10^{7} \mathrm{CFU} / \mathrm{mL}\right)$ to $\sim 0.3\left(\sim 9.5 \times 10^{6} \mathrm{CFU} / \mathrm{mL}\right)$ within $5 \mathrm{~min}$ under a concentration of $50 \mu \mathrm{g} / \mathrm{mL}$. The dose-dependent experiments showed that $0.5 \mu \mathrm{g} / \mathrm{mL}$ ClyR kills $\sim 80 \%$ viable bacteria after treatment for $40 \mathrm{~min}$, and $<10 \%$ survival rate is observed when treated with $5 \mu \mathrm{g} / \mathrm{mL}$ ClyR (Figure 1b). Moreover, treatment with $50 \mu \mathrm{g} / \mathrm{mL}$ ClyR for only $0.5 \mathrm{~min}$ eradicated $\sim 50 \%$ viable bacteria, and $>90 \%$ bacterial cells were killed after exposure to ClyR for $1 \mathrm{~min}$ (Figure 1c), suggesting a robust and rapid bactericidal activity. We further assessed the susceptibility of another 15 E. faecalis strains to ClyR, and results showed that ClyR is highly active against all strains tested (Figure 1d), with decreases in $\mathrm{OD}_{600}$ from 0.2 to $\sim 0.5$.
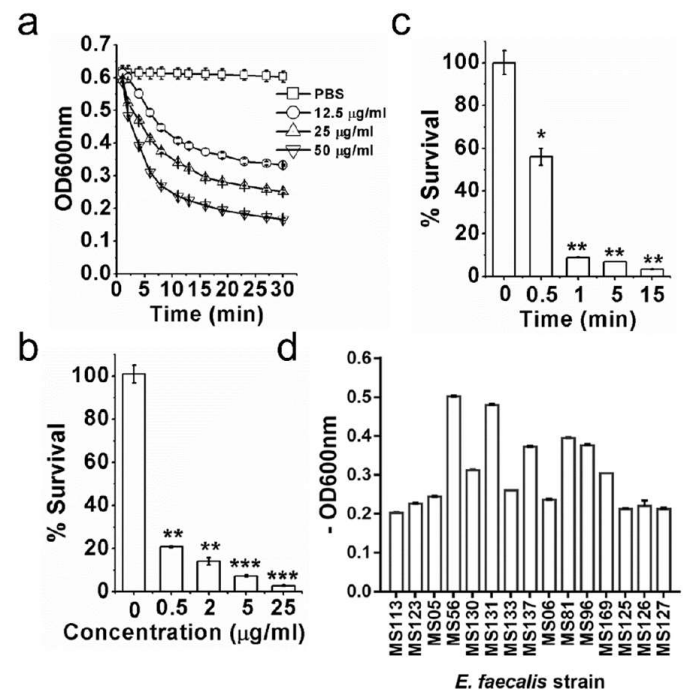

Figure 1. Robust and rapid bactericidal activity of ClyR against planktonic E. faecalis. (a) Lysis curves of ClyR against E. faecalis ATCC 51299. Bacterial cells are washed with phosphate-buffered saline (PBS) and mixed with various concentrations of ClyR $(0,12.5,25$, and $50 \mu \mathrm{g} / \mathrm{mL})$, the decrease of $\mathrm{OD}_{600}$ is monitored by a microplate reader for $30 \mathrm{~min}$ at $37^{\circ} \mathrm{C}$. (b) Dose-dependent killing efficacy of ClyR against E. faecalis ATCC51299. Bacterial cells are washed with PBS and treated with various concentrations of $\mathrm{ClyR}(0,0.5,2,5$, and $25 \mu \mathrm{g} / \mathrm{mL})$ for $40 \mathrm{~min}$ at $37^{\circ} \mathrm{C}$, the viable cell number after each 
treatment is determined by plating on brain heart infusion (BHI) agar. (c) Time-dependent killing efficacy of ClyR against $E$. faecalis ATCC51299. Bacterial cells are washed with PBS and treated with $50 \mu \mathrm{g} / \mathrm{mL}$ of ClyR at $37^{\circ} \mathrm{C}$ for different times $(0,0.5,1,5$, and $15 \mathrm{~min})$, the viable cell number after each treatment is determined by plating on BHI agar. (d) Susceptibility of multiple E. faecalis strains to ClyR. The result of each treatment is compared with that of the PBS-treated controls by Two-tailed Student's $t$ test. Data is shown as mean \pm standard deviation, and ${ }^{*} p<0.05 ;{ }^{* *} p<0.01$; ${ }^{* *} p<0.001$.

In order to know the morphological change of E. faecalis after exposure to ClyR, we investigated the integrity of E. faecalis cells after treatment with various concentrations of ClyR by TEM. Results showed that the ratio of the number of cells with intact cell wall to the number of ruptured cells declined along with increasing concentration of ClyR (Figure 2, left panels). The inserted figures clearly showed that native E. faecalis bacteria have a holonomic and uniform cell wall, while the bacteria after treatment with ClyR exhibit destructed and heavily deformed cell morphology, resulting in the presence of many "ghost cells" (Figure 2, right panels). This observation is quite consistent with the phenomenon of lysin-mediated osmotic cell lysis reported elsewhere [33].

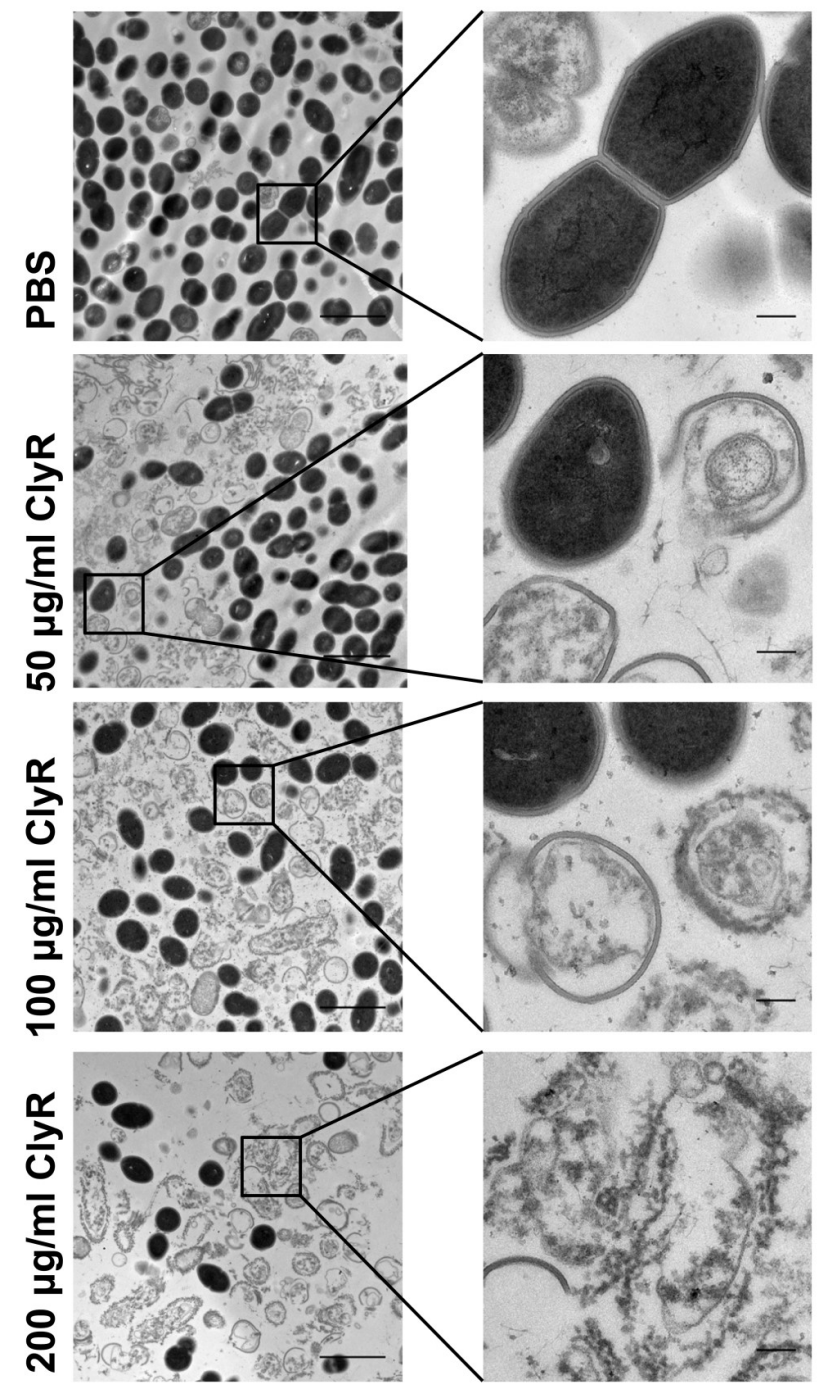

Figure 2. Morphology of E. faecalis after exposure to ClyR. E. faecalis ATCC 51299 cells are washed with PBS and treated with various concentrations of ClyR $(0,50,100$, and $200 \mu \mathrm{g} / \mathrm{mL})$ for $1 \mathrm{~h}$ at room temperature. The morphology of bacterial cells after each treatment is observed by TEM. Scale bars: left panel: $2 \mu \mathrm{m}$; right panel: $20 \mathrm{~nm}$. 


\subsection{ClyR Is Active against E. faecalis Biofilm In Vitro}

Next, we assessed the degradation efficacy of ClyR against established E. faecalis biofilms. The crystal violet staining assay showed that ClyR causes a significant dissociation of mature biofilms in a dose-dependent manner (Figure 3a). Consequently, the number of viable bacteria recovered from biofilms decreased along with the increased dose of ClyR (Figure 3b), with less than $40 \%$ (from $2.17 \times 10^{7} \mathrm{CFU} / \mathrm{mL}$ to $8.2 \times 10^{6} \mathrm{CFU} / \mathrm{mL}$ ) and $10 \%\left(\right.$ from $2.17 \times 10^{7} \mathrm{CFU} / \mathrm{mL}$ to $2.2 \times 10^{6} \mathrm{CFU} / \mathrm{mL}$ ) survival after treatment with $50 \mu \mathrm{g} / \mathrm{mL}$ and $200 \mu \mathrm{g} / \mathrm{mL}$ ClyR for $1 \mathrm{~h}$, respectively.
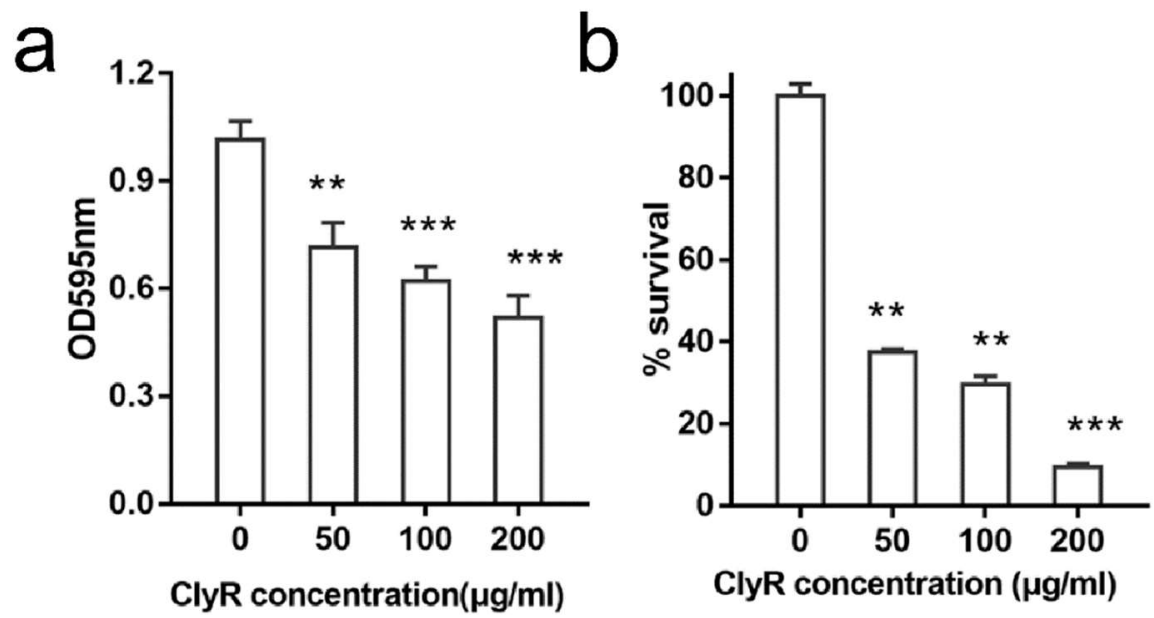

Figure 3. High activity of ClyR against E. faecalis biofilm. (a) Crystal violet staining analysis of E. faecalis biofilms. E. faecalis ATCC 51299 cells are cultured in BHI supplemented with 3\% glucose (BHIG) for $24 \mathrm{~h}$ to allow biofilm formation, after washing with PBS, biofilms are treated with various concentrations of ClyR $(0,50,100$, and $200 \mu \mathrm{g} / \mathrm{mL})$ at $37^{\circ} \mathrm{C}$ for $1 \mathrm{~h}$, residual biofilms are stained with $0.1 \%$ crystal violet and detected at $\mathrm{OD}_{595}$ by a microplate reader after resolved by ethanol. (b) Survival rate of E. faecalis biofilms after treatment with ClyR. 24 h-aged E. faecalis ATCC 51299 biofilms are treated with various concentrations of $\operatorname{ClyR}(0,50,100$, and $200 \mu \mathrm{g} / \mathrm{mL})$ at $37^{\circ} \mathrm{C}$ for $1 \mathrm{~h}$, the viable cells after each treatment is determined and compared with that of PBS treated controls by Two-tailed Student's t test. Data is shown as mean \pm standard deviation, and ${ }^{* *} p<0.01$; ${ }^{* *} p<0.001$.

\subsection{Microscopy Analysis of E. faecalis Biofilms after Exposure to ClyR In Vitro}

In order to investigate the mechanism and the dynamics of ClyR against E. faecalis biofilms, we analyzed the phenotypic morphology and structure of E. faecalis biofilms after exposure to ClyR. The SEM images showed that ClyR causes a direct cell lysis within biofilms and thus gives rise to the rapid degradation of mature biofilm, displaying rough and shrink cell surfaces (Figure 4, arrow). By contrast, native E. faecalis bacteria within biofilms exhibited a smooth and full morphological character (Figure 4, upper). 


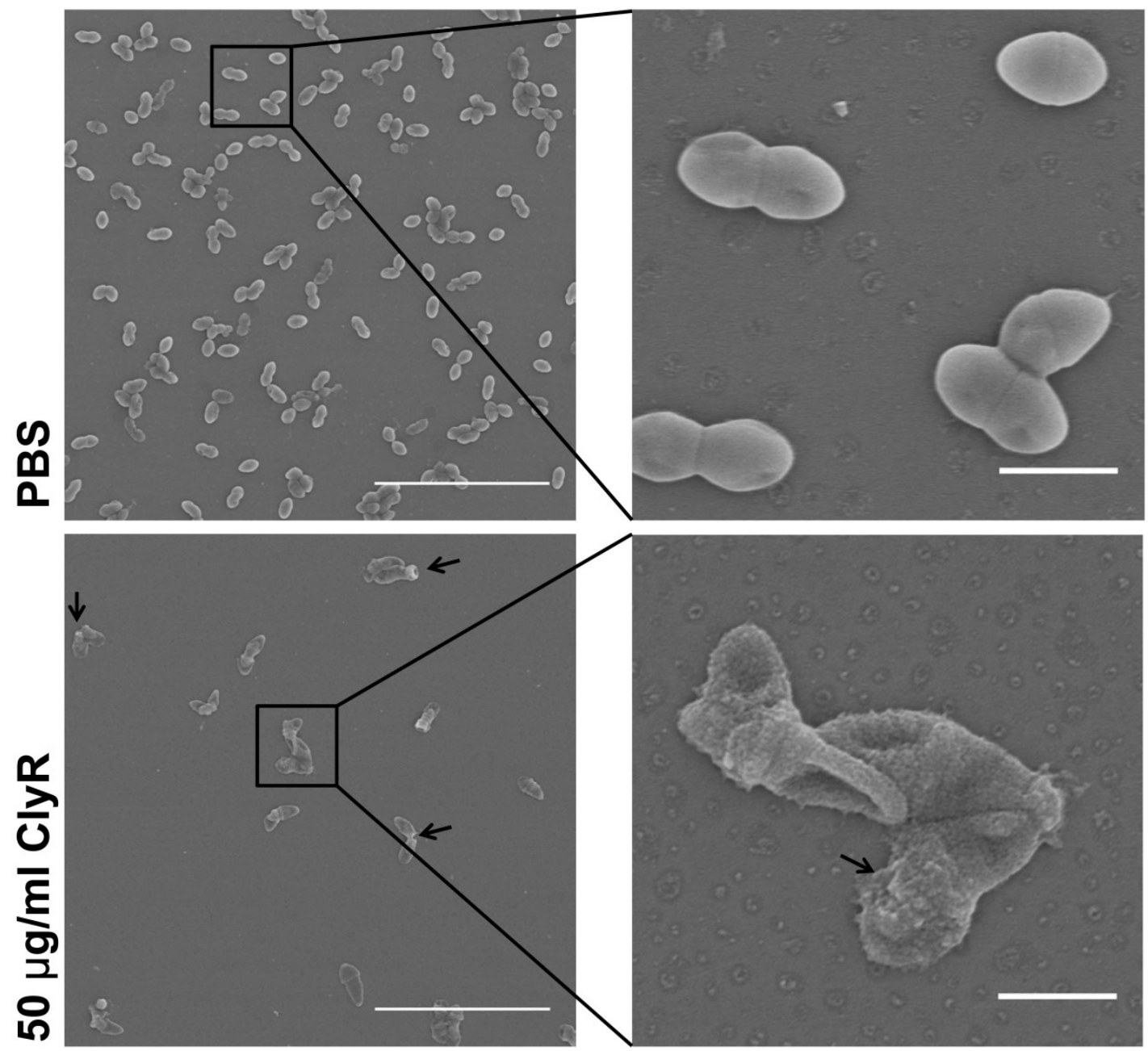

Figure 4. SEM analysis of E. faecalis biofilms after exposure to ClyR. E. faecalis ATCC 51299 is cultured in BHIG on glass coverslips for $24 \mathrm{~h}$ to allow biofilms, after washing with PBS, biofilms are treated with $50 \mu \mathrm{g} / \mathrm{mL}$ ClyR for $1 \mathrm{~h}$ at $37^{\circ} \mathrm{C}$, the residual biofilms are sampled and analyzed by SEM. PBS treated groups are used as controls. Scale bars: left panel: $10 \mu \mathrm{m}$; right panel: $1 \mu \mathrm{m}$.

Further, we observed the structure of E. faecalis biofilms by using LIVE/DEAD dye, by which the living bacteria within biofilms were labeled as green, while the dead bacteria are labelled as red. As shown in Figure 5a, E. faecalis biofilms cultured for $24 \mathrm{~h}$ showed heavy but heterogeneous biofilm layers showing bright green fluorescence. After treatment with $100 \mu \mathrm{g} / \mathrm{mL}$ ClyR for $1 \mathrm{~h}$, a large number of red spots, representing dead bacterial cells, were observed within biofilms (Figure $5 b$, left), showing a weakened biofilm with many dead but still adhered cells (Figure $5 b$, right). However, in E. faecalis biofilms after treatment with $200 \mu \mathrm{g} / \mathrm{mL}$ ClyR, few viable bacteria could be found, showing a scattered and residual biofilm with few live and dead cells adhered (Figure $5 \mathrm{c}$ ). These results suggested that ClyR causes death and dysfunction to E. faecalis bacteria within biofilms through direct cell lysis, and then the heterogenization and exfoliation of bacterial biofilms, and finally the formation of degraded biofilms with few adhered bacterial cells. 
a

2D image

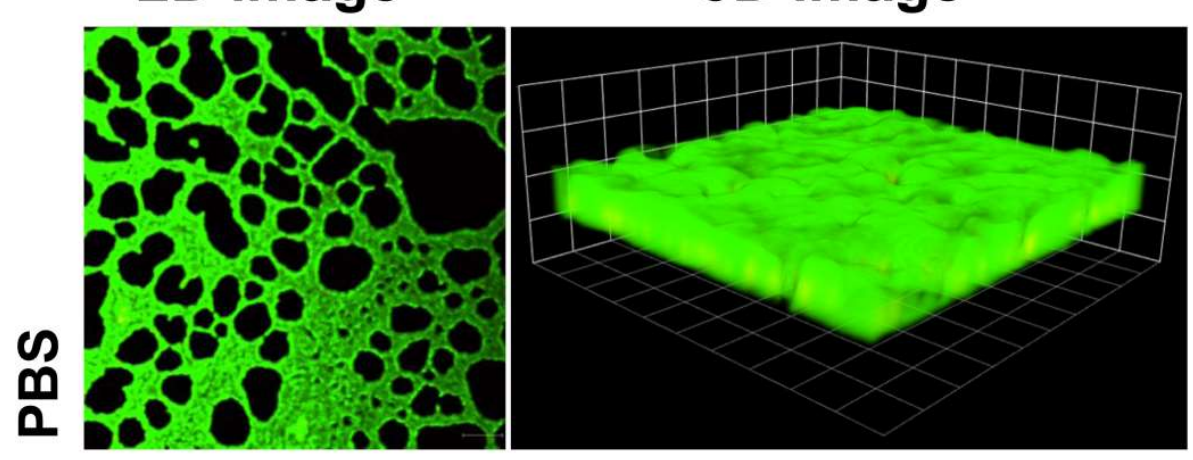

b
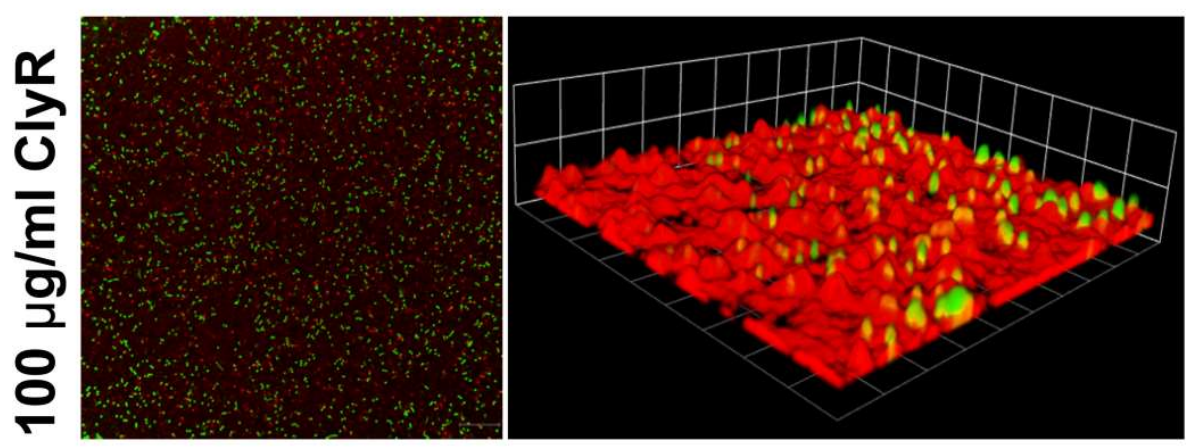

C

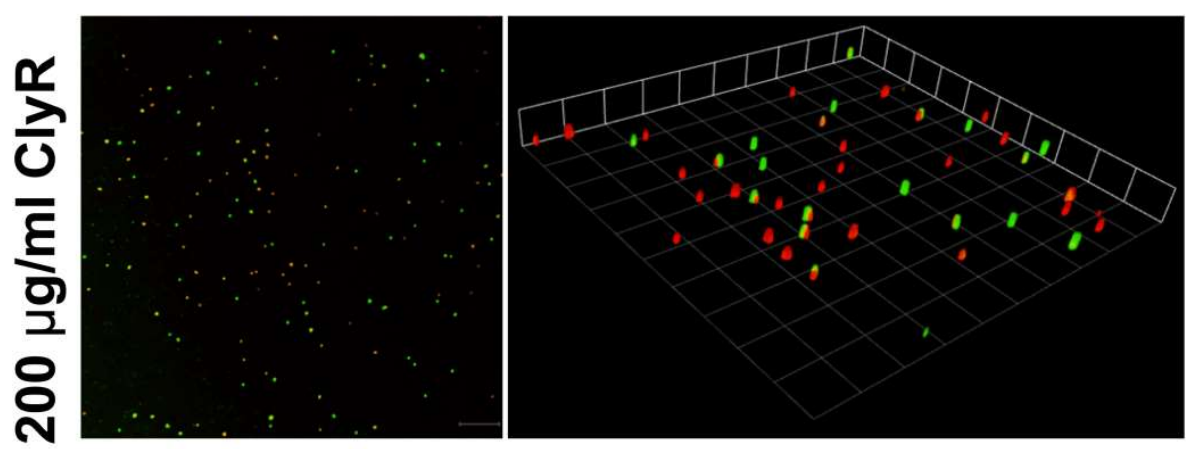

Figure 5. Confocal laser scanning microscope (CLSM) analysis of E. faecalis biofilms after exposure to 0 (a), $100 \mu \mathrm{g} / \mathrm{mL}$ (b) or $200 \mu \mathrm{g} / \mathrm{mL}$ (c) ClyR. E. faecalis ATCC 51299 biofilms grown for $24 \mathrm{~h}$ are treated with different concentrations of ClyR $(0,100$ and $200 \mu \mathrm{g} / \mathrm{mL})$ for $1 \mathrm{~h}$ at $37^{\circ} \mathrm{C}$. After washing with PBS, biofilms are stained with LIVE/DEAD reagent and analyzed by confocal laser scanning microscopy. Scale bars: $30 \mu \mathrm{m}$

\subsection{Ex Vivo Dentin Slice Biofilm Model}

Since E. faecalis is a major pathogen responsible for refractory periapical periodontitis, we further compared the anti-biofilm capacity of ClyR in an ex vivo dentin slice biofilm model with that of calcium hydroxide $\left(\mathrm{Ca}(\mathrm{OH})_{2}\right)$, a chemical reagent that is commercially used for the treatment of a variety of dental pulp and periapical diseases [34-36]. E. faecalis ATCC 51299 is highly resistant to vancomycin (MIC $=32 \mu \mathrm{g} / \mathrm{mL}$ ) but susceptible to ampicillin (MIC $=2 \mu \mathrm{g} / \mathrm{mL}$, Table S1), therefore, we took ampicillin into comparison. Results showed that a high concentration of ampicillin of up to $50 \mathrm{mg} / \mathrm{mL}$ (25,000-fold of MIC) did not show any biofilm removal efficacy (Figure 6). However, a low concentration of ClyR (50 $\mathrm{\mu g} / \mathrm{mL})$ killed $>90 \%$ viable bacteria within biofilms within $1 \mathrm{~h}$, comparable to that of a high concentration of $\mathrm{Ca}(\mathrm{OH})_{2}$ (Figure 6). 


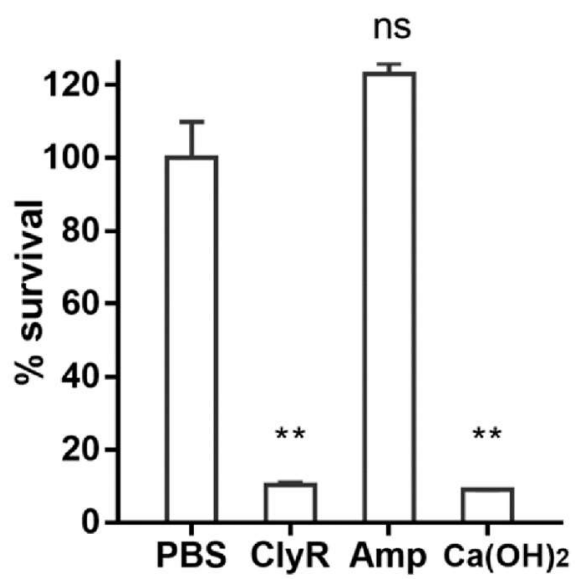

Figure 6. Robust biofilm removal efficacy of ClyR in an ex vivo dental model. E. faecalis ATCC 51299 biofilms grown on dentin slices are treated either with $50 \mu \mathrm{g} / \mathrm{mL} \mathrm{ClyR,} 50 \mathrm{mg} / \mathrm{mL}$ ampicillin, or $0.5 \% \mathrm{Ca}(\mathrm{OH})_{2}$ for $1 \mathrm{~h}$ at $37^{\circ} \mathrm{C}$, after washing with PBS, viable cell within biofilm after each treatment is recovered by plating on BHI agar, and compared with that of PBS treated controls by Two-tailed Student's $t$ test. Data is shown as mean \pm standard deviation, and ns: not significant; ${ }^{* *} p<0.01$.

\section{Discussion}

E. faecalis is a commensal opportunistic pathogen in the intestines of humans and animals and can also be found in the mouth and vaginal tract [37]. Under certain conditions, it can spread to other sites of body and cause invasive infections, such as neonatal sepsis, peritonitis, wound and urinary tract infections, and even life-threatening nosocomial infections [38]. However, due to its intrinsic resistance to multiple first-line antimicrobials [39] and easy access to acquiring enhanced resistance by forming biofilm or hosting horizontal transferred antimicrobial genes [40], treatment of an infection caused by E. faecalis is difficult, with limited therapeutic options [41]. In the present study, we reported that a chimeric lysin, ClyR, has high bacteriocidal activity against multiple planktonic E. faecalis strains, and exhibits good efficacy in removing E. faecalis biofilms in vitro, providing a potential alternative to treat E. faecalis infections.

ClyR is a chimeric lysin with a broad bactericidal spectrum, based on our previous studies, including S. pyogenes, S. agalactiae, S. dysgalactiae, S. mutans, S. pneumoniae, S. suis, S. aureus, and E. faecalis [28]. We further demonstrated here that ClyR is highly active against multiple planktonic E. faecalis strains (Figure 1d), including vancomycin-resistant strain ATCC 51299 , killing $>90 \%$ bacterial cells within only $1 \mathrm{~min}$ (Figure 1c), and the effective concentration of ClyR is low to $0.5 \mu \mathrm{g} / \mathrm{mL}$ (Figure 1b). Because the killing mechanism of ClyR is based on the direct digestion of bacterial peptidoglycan linkages and thus the osmotic cell lysis (Figure 2), absolutely differing from that of conventional antibiotics, the possibility that $E$. faecalis may gain resistance to $C l y R$ is low, similar to the observations reported by other researchers that bacterial strains maintain susceptibility to lysins after continuous exposure [42,43]. Taking into account the robust tolerance of ClyR to various environmental factors, including a broad suitable $\mathrm{pH}$ range of 5-11, unsusceptible to EDTA (high up to $50 \mathrm{mM}$ ) and $\mathrm{NaCl}$ (up to $1000 \mathrm{mM}$ ), good protection in the animal infection model [28], and low cytotoxicity [27], ClyR may represent a good candidate for treating infections caused by multidrug resistant $E$. faecalis.

Our data also showed that ClyR has high anti-biofilm activity against E. faecalis in a dose-dependent manner, with $<40 \%$ survival rate observed within $E$. faecalis biofilms cultured under rich nutrition conditions after treatment with $50 \mu \mathrm{g} / \mathrm{mL}$ ClyR for $1 \mathrm{~h}$ (Figure 3). Further analysis revealed that ClyR causes an obvious deformation and destruction of bacterial cells within biofilms through direct peptidoglycan hydrolysis (Figure 4), a phenomenon similar to the action of $\mathrm{ClyH}$ against S. aureus biofilms [19]. The fluorescence microscopy analysis clearly illustrated that the structural integrity and homogeneity of E. faecalis biofilms decline gradually with the increased dose of ClyR 
(Figure 5). Interestingly, large amounts of dead cells remain adhered and involved in biofilms after treatment with a middle dose of ClyR $(100 \mu \mathrm{g} / \mathrm{mL}$, Figure $5 \mathrm{~b})$, while only a few dead cells were present in the scattered biofilm after treatment with a high dose of ClyR (200 $\mu \mathrm{g} / \mathrm{mL}$, Figure 5c), suggesting ClyR degrades E. faecalis biofilm in a layer-by-layer manner, similar to the mechanism involved in PlyC's activity against S. pyogenes biofilms [15]. As far as we know, this is the first time the interaction between a lysin and E. faecalis biofilm in vitro has been reported. Although the interaction dynamics between lysins and bacterial biofilms in the site of an infection are, to date, still far from revealed, our present data supports new insight into the mechanism a lysin with extended lytic spectrum utilized to kill sessile E. faecalis.

E. faecalis is also one of the leading causes of periapical endodontic lesions due to its strong tolerance and biofilm-forming capacity that can survive the changing $\mathrm{pH}$, temperature, and osmotic pressure in the oral cavity. Currently, few options are available for the treatment of refractory periapical periodontitis caused by $E$. faecalis $[3,4] . \mathrm{Ca}(\mathrm{OH})_{2}$ has been used extensively as a routine intracanal medicament to disinfect the entire root canal system in the treatment of endodontics and dental traumatology $[16,44]$. Therefore, in the present study, we compared the anti-biofilm capacity of ClyR against $E$. faecalis biofilm formed in dentine slices with that of $\mathrm{Ca}(\mathrm{OH})_{2}$ and ampicillin. Encouragingly, ClyR showed a significantly high biofilm removal efficacy, killing $>90 \%$ viable bacterial cells within biofilms at a low dose of $50 \mu \mathrm{g} / \mathrm{mL}$, much better than 25,000× MIC ampicillin, but similar to $\mathrm{Ca}(\mathrm{OH})_{2}$, (Figure 6), suggesting it as a potent alternative in endodontic therapy associated with E. faecalis.

Compared with $\mathrm{Ca}(\mathrm{OH})_{2}$, there are several advantages to introducing ClyR into endodontic applications although its in vivo anti-biofilm activity still needs to be established. On one hand, ClyR will only eliminate susceptible bacteria without disturbing other microbes involved in the oral microbiota, and the risk of resistance generation is low. However, many bacterial species recovered from the microbiota with refractory apical periodontitis already have resistance to $\mathrm{Ca}(\mathrm{OH})_{2}[2,45]$, and are thus responsible for many endodontic failures [4]. On the other hand, ClyR is proteinaceous with rare cytotoxicity and stimulation to the host immunity. Meanwhile, $\mathrm{Ca}(\mathrm{OH})_{2}$ has multiple potential side effects, including the formation of calcite granulations [46], reduced flexural strength and lower fracture resistance to dentine $[47,48]$, calcium ions diffusion from $\mathrm{Ca}(\mathrm{OH})_{2}$-containing materials in endodontically-treated teeth [49], and detrimental effects on periodontal tissues and host immunity [50-52]. Taking the good stability and rapid bactericidal capacity of ClyR into consideration, one can easily find that $\mathrm{ClyR}$ represents a potential alternative to $\mathrm{Ca}(\mathrm{OH})_{2}$ in the management of endodontic problems.

Our previous study has reported the anti-biofilm activity of ClyR against S. mutans, the major pathogen for caries, in vitro and in a mouse colonization model [27]. One important finding was that ClyR significantly reduces the colonization of $S$. mutans in the oral cavity without eliciting specific antibodies. Together with our present data showing high lytic activity of ClyR against E. faecalis and its biofilm, our researches highlight the potent application of ClyR in treating dental-associated diseases in oral environments. One does not need to worry about the effects of antibodies and thus derived concerns on the host immunity, a propriety that is of special importance in the development and transformation of lysin-derived therapies.

In conclusion, we report here the high activity of ClyR, a chimeric lysin with extended streptococcal lytic spectrum, against planktonic and sessile E. faecalis cells in vitro and in an ex vivo dental model. The robust bactericidal activity of ClyR against E. faecalis, together with the reported good protective efficacy in the infection model and high activity against $S$. mutans biofilms, suggests that ClyR may be a good alternative in treating infection caused by E. faecalis, especially in the oral environment.

Supplementary Materials: Supplementary materials can be found at http:/ /www.mdpi.com/1999-4915/10/6/290/s1.

Author Contributions: W.L., H.Y., Y.G. and S.W. conducted the experiments. W.L., H.Y., Y.G., S.W., Y.L. and H.W. analyzed the data. W.L., H.Y., Y.L. and H.W. designed the experiment. W.L., H.Y., Y.L. and H.W. wrote the paper. 
Acknowledgments: This work was supported by the National Natural Science Foundation of China (No. 31770192 to H.Y., and No. 31570175 to H.W.), and the Youth Innovation Promotion Association CAS (to H.Y.). We are grateful to Ding Gao, Pei Zhang and Bichao Xu from the Core Facility and Technical Support, Wuhan Institute of Virology for their assistance in image studies.

Conflicts of Interest: The chimeolysin reported here originated from Wuhan Scithera Microbial Technologies Co., Ltd., in which H.Y. and H.W. have financial interests.

\section{References}

1. Creti, R.; Imperi, M.; Bertuccini, L.; Fabretti, F.; Orefici, G.; Di Rosa, R.; Baldassarri, L. Survey for virulence determinants among Enterococcus faecalis isolated from different sources. J. Med. Microbiol. 2004, 53, 13-20. [CrossRef] [PubMed]

2. Sunde, P.T.; Olsen, I.; Debelian, G.J.; Tronstad, L. Microbiota of periapical lesions refractory to endodontic therapy. J. Endod. 2002, 28, 304-310. [CrossRef] [PubMed]

3. Stuart, C.H.; Schwartz, S.A.; Beeson, T.J.; Owatz, C.B. Enterococcus faecalis: Its role in root canal treatment failure and current concepts in retreatment. J. Endod. 2006, 32, 93-98. [CrossRef] [PubMed]

4. Love, R.M. Enterococcus faecalis-A mechanism for its role in endodontic failure. Int. Endod. J. 2001, 34, 399-405. [CrossRef] [PubMed]

5. Stewart, P.S.; Costerton, J.W. Antibiotic resistance of bacteria in biofilms. Lancet 2001, 358, 135-138. [CrossRef]

6. Gomez-Gil, R.; Romero-Gomez, M.P.; Garcia-Arias, A.; Ubeda, M.G.; Busselo, M.S.; Cisterna, R.; Gutierrez-Altes, A.; Mingorance, J. Nosocomial outbreak of linezolid-resistant Enterococcus faecalis infection in a tertiary care hospital. Diagn. Microbiol. Infect. Dis. 2009, 65, 175-179. [CrossRef] [PubMed]

7. Domenech, M.; Ramos-Sevillano, E.; Garcia, E.; Moscoso, M.; Yuste, J. Biofilm formation avoids complement immunity and phagocytosis of Streptococcus pneumoniae. Infect. Immun. 2013, 81, 2606-2615. [CrossRef] [PubMed]

8. Hanke, M.L.; Kielian, T. Deciphering mechanisms of staphylococcal biofilm evasion of host immunity. Front. Cell Infect. Microbiol. 2012, 2, 62. [CrossRef] [PubMed]

9. Sahm, D.F.; Kissinger, J.; Gilmore, M.S.; Murray, P.R.; Mulder, R.; Solliday, J.; Clarke, B. In vitro susceptibility studies of vancomycin-resistant Enterococcus faecalis. Antimicrob. Agents Chemother. 1989, 33, 1588-1591. [CrossRef] [PubMed]

10. Munoz-Price, L.S.; Lolans, K.; Quinn, J.P. Emergence of resistance to daptomycin during treatment of vancomycin-resistant Enterococcus faecalis infection. Clin. Infect. Dis. 2005, 41, 565-566. [CrossRef] [PubMed]

11. Baldassarri, L.; Creti, R.; Recchia, S.; Imperi, M.; Facinelli, B.; Giovanetti, E.; Pataracchia, M.; Alfarone, G.; Orefici, G. Therapeutic failures of antibiotics used to treat macrolide-susceptible Streptococcus pyogenes infections may be due to biofilm formation. J. Clin. Microbiol. 2006, 44, 2721-2727. [CrossRef] [PubMed]

12. Kayaoglu, G.; Orstavik, D. Virulence factors of Enterococcus faecalis: Relationship to endodontic disease. Crit. Rev. Oral Biol. Med. 2004, 15, 308-320. [CrossRef] [PubMed]

13. Larpin, Y.; Oechslin, F.; Moreillon, P.; Resch, G.; Entenza, J.M.; Mancini, S. In vitro characterization of PlyE146, a novel phage lysin that targets Gram-negative bacteria. PLoS ONE 2018, 13, e0192507. [CrossRef] [PubMed]

14. Loeffler, J.M.; Nelson, D.; Fischetti, V.A. Rapid killing of streptococcus pneumoniae with a bacteriophage cell wall hydrolase. Science 2001, 294, 2170-2172. [CrossRef] [PubMed]

15. Shen, Y.; Koller, T.; Kreikemeyer, B.; Nelson, D.C. Rapid degradation of Streptococcus pyogenes biofilms by PlyC, a bacteriophage-encoded endolysin. J. Antimicrob. Chemother. 2013, 68, 1818-1824. [CrossRef] [PubMed]

16. Siqueira, J.F., Jr.; Lopes, H.P. Mechanisms of antimicrobial activity of calcium hydroxide: A critical review. Int. Endod. J. 1999, 32, 361-369. [CrossRef] [PubMed]

17. Thandar, M.; Lood, R.; Winer, B.Y.; Deutsch, D.R.; Euler, C.W.; Fischetti, V.A. Novel Engineered Peptides of a Phage Lysin as Effective Antimicrobials against Multidrug-Resistant Acinetobacter baumannii. Antimicrob. Agents Chemother. 2016, 60, 2671-2679. [CrossRef] [PubMed]

18. Schuch, R.; Khan, B.K.; Raz, A.; Rotolo, J.A.; Wittekind, M. Bacteriophage Lysin CF-301, a Potent Antistaphylococcal Biofilm Agent. Antimicrob. Agents Chemother. 2017, 61, e02666-16. [CrossRef] [PubMed]

19. Yang, H.; Zhang, Y.; Huang, Y.; Yu, J.; Wei, H. Degradation of methicillin-resistant Staphylococcus aureus biofilms using a chimeric lysin. Biofouling 2014, 30, 667-674. [CrossRef] [PubMed] 
20. Yang, H.; Zhang, H.; Wang, J.; Yu, J.; Wei, H. A novel chimeric lysin with robust antibacterial activity against planktonic and biofilm methicillin-resistant Staphylococcus aureus. Sci. Rep. 2017, 7, 40182. [CrossRef] [PubMed]

21. Sass, P.; Bierbaum, G. Lytic activity of recombinant bacteriophage $\varphi 11$ and $\varphi 12$ endolysins on whole cells and biofilms of Staphylococcus aureus. Appl. Environ. Microbiol. 2007, 73, 347-352. [CrossRef] [PubMed]

22. Son, J.S.; Lee, S.J.; Jun, S.Y.; Yoon, S.J.; Kang, S.H.; Paik, H.R.; Kang, J.O.; Choi, Y.J. Antibacterial and biofilm removal activity of a podoviridae Staphylococcus aureus bacteriophage SAP-2 and a derived recombinant cell-wall-degrading enzyme. Appl. Microbiol. Biotechnol. 2010, 86, 1439-1449. [CrossRef] [PubMed]

23. Singh, P.K.; Donovan, D.M.; Kumar, A. Intravitreal injection of the chimeric phage endolysin ply187 protects mice from Staphylococcus aureus endophthalmitis. Antimicrob. Agents Chemother. 2014, 58, 4621-4629. [CrossRef] [PubMed]

24. Nair, S.; Desai, S.; Poonacha, N.; Vipra, A.; Sharma, U. Antibiofilm activity and synergistic inhibition of Staphylococcus aureus biofilms by bactericidal protein p128 in combination with antibiotics. Antimicrob. Agents Chemother. 2016, 60, 7280-7289. [PubMed]

25. Meng, X.; Shi, Y.; Ji, W.; Meng, X.; Zhang, J.; Wang, H.; Lu, C.; Sun, J.; Yan, Y. Application of a bacteriophage lysin to disrupt biofilms formed by the animal pathogen Streptococcus suis. Appl. Environ. Microbiol. 2011, 77, 8272-8279. [CrossRef] [PubMed]

26. Domenech, M.; Garcia, E.; Moscoso, M. In vitro destruction of Streptococcus pneumoniae biofilms with bacterial and phage peptidoglycan hydrolases. Antimicrob. Agents Chemother. 2011, 55, 4144-4148. [CrossRef] [PubMed]

27. Yang, H.; Bi, Y.; Shang, X.; Wang, M.; Linden, S.B.; Li, Y.; Li, Y.; Nelson, D.C.; Wei, H. Antibiofilm activities of a novel chimeolysin against Streptococcus mutans under physiological and cariogenic conditions. Antimicrob. Agents Chemother. 2016, 60, 7436-7443. [PubMed]

28. Yang, H.; Linden, S.B.; Wang, J.; Yu, J.; Nelson, D.C.; Wei, H. A chimeolysin with extended-spectrum streptococcal host range found by an induced lysis-based rapid screening method. Sci. Rep. 2015, 5, 17257. [CrossRef] [PubMed]

29. Cheng, M.; Zhang, Y.; Li, X.; Liang, J.; Hu, L.; Gong, P.; Zhang, L.; Cai, R.; Zhang, H.; Ge, J.; et al. Endolysin LysEF-P10 shows potential as an alternative treatment strategy for multidrug-resistant Enterococcus faecalis infections. Sci. Rep. 2017, 7, 10164. [CrossRef] [PubMed]

30. Proenca, D.; Leandro, C.; Garcia, M.; Pimentel, M.; Sao-Jose, C. EC300: A phage-based, bacteriolysin-like protein with enhanced antibacterial activity against Enterococcus faecalis. Appl. Microbiol. Biotechnol. 2015, 99, 5137-5149. [CrossRef] [PubMed]

31. Clinical and Laboratory Standards Institute. Methods for Dilution Antimicrobial Susceptibility Tests for Bacteria that Grow Aerobically, 10th ed.; Approved Standard m07-a10; Clinical and Laboratory Standards Institute: Wayne, PA, USA, 2015.

32. Herrera, D.R.; Tay, L.Y.; Rezende, E.C.; Kozlowski, V.A., Jr.; Santos, E.B. In vitro antimicrobial activity of phytotherapic Uncaria tomentosa against endodontic pathogens. J. Oral Sci. 2010, 52, 473-476. [CrossRef] [PubMed]

33. Fischetti, V.A. Bacteriophage lysins as effective antibacterials. Curr. Opin. Microbiol. 2008, 11, $393-400$. [CrossRef] [PubMed]

34. Siqueira, J.F., Jr.; de Uzeda, M. Disinfection by calcium hydroxide pastes of dentinal tubules infected with two obligate and one facultative anaerobic bacteria. J. Endod. 1996, 22, 674-676. [CrossRef]

35. Ricucci, D.; Martorano, M.; Bate, A.L.; Pascon, E.A. Calculus-like deposit on the apical external root surface of teeth with post-treatment apical periodontitis: Report of two cases. Int. Endod. J. 2005, 38, 262-271. [CrossRef] [PubMed]

36. Caliskan, M.K.; Sen, B.H. Endodontic treatment of teeth with apical periodontitis using calcium hydroxide: A long-term study. Endod. Dent. Traumatol. 1996, 12, 215-221. [CrossRef] [PubMed]

37. Klein, G. Taxonomy, ecology and antibiotic resistance of enterococci from food and the gastro-intestinal tract. Int. J. Food Microbiol. 2003, 88, 123-131. [CrossRef]

38. Gilmore, M.S.; Lebreton, F.; van Schaik, W. Genomic transition of enterococci from gut commensals to leading causes of multidrug-resistant hospital infection in the antibiotic era. Curr. Opin. Microbiol. 2013, 16, 10-16. [CrossRef] [PubMed] 
39. Hammerum, A.M. Enterococci of animal origin and their significance for public health. Clin. Microbiol. Infect. 2012, 18, 619-625. [CrossRef] [PubMed]

40. French, G.L. The continuing crisis in antibiotic resistance. Int. J. Antimicrob. Agents 2010, 36 (Suppl. 3), S3-S7. [CrossRef]

41. Werner, G.; Coque, T.M.; Franz, C.M.; Grohmann, E.; Hegstad, K.; Jensen, L.; van Schaik, W.; Weaver, K. Antibiotic resistant enterococci-tales of a drug resistance gene trafficker. Int. J. Med. Microbiol. 2013, 303, 360-379. [CrossRef] [PubMed]

42. Gilmer, D.B.; Schmitz, J.E.; Euler, C.W.; Fischetti, V.A. Novel bacteriophage lysin with broad lytic activity protects against mixed infection by Streptococcus pyogenes and methicillin-resistant Staphylococcus aureus. Antimicrob. Agents Chemother. 2013, 57, 2743-2750. [CrossRef] [PubMed]

43. Schuch, R.; Lee, H.M.; Schneider, B.C.; Sauve, K.L.; Law, C.; Khan, B.K.; Rotolo, J.A.; Horiuchi, Y.; Couto, D.E.; Raz, A.; et al. Combination therapy with lysin CF-301 and antibiotic is superior to antibiotic alone for treating methicillin-resistant Staphylococcus aureus-induced murine bacteremia. J. Infect. Dis. 2014, 209, 1469-1478. [CrossRef] [PubMed]

44. Mohammadi, Z.; Dummer, P.M. Properties and applications of calcium hydroxide in endodontics and dental traumatology. Int. Endod. J. 2011, 44, 697-730. [CrossRef] [PubMed]

45. Evans, M.; Davies, J.K.; Sundqvist, G.; Figdor, D. Mechanisms involved in the resistance of Enterococcus faecalis to calcium hydroxide. Int. Endod. J. 2002, 35, 221-228. [CrossRef] [PubMed]

46. Holland, R.; de Souza, V.; Nery, M.J.; Otoboni Filho, J.A.; Bernabe, P.F.; Dezan Junior, E. Reaction of rat connective tissue to implanted dentin tubes filled with mineral trioxide aggregate or calcium hydroxide. J. Endod. 1999, 25, 161-166. [CrossRef]

47. Rosenberg, B.; Murray, P.E.; Namerow, K. The effect of calcium hydroxide root filling on dentin fracture strength. Dent. Traumatol. 2007, 23, 26-29. [CrossRef] [PubMed]

48. Doyon, G.E.; Dumsha, T.; von Fraunhofer, J.A. Fracture resistance of human root dentin exposed to intracanal calcium hydroxide. J. Endod. 2005, 31, 895-897. [CrossRef] [PubMed]

49. Rehman, K.; Saunders, W.P.; Foye, R.H.; Sharkey, S.W. Calcium ion diffusion from calcium hydroxide-containing materials in endodontically-treated teeth: An in vitro study. Int. Endod. J. 1996, 29, 271-279. [CrossRef] [PubMed]

50. Eldeniz, A.U.; Mustafa, K.; Orstavik, D.; Dahl, J.E. Cytotoxicity of new resin-, calcium hydroxide- and silicone-based root canal sealers on fibroblasts derived from human gingiva and 1929 cell lines. Int. Endod. J. 2007, 40, 329-337. [CrossRef] [PubMed]

51. Spangberg, L. Biological effects of root canal filling materials. 7. Reaction of bony tissue to implanted root canal filling material in guineapigs. Odontol. Tidskr. 1969, 77, 133-159. [PubMed]

52. Spangberg, L. Biological effects of root canal filling materials. 5. Toxic effect in vitro of root canal filling materials on HeLa cells and human skin fibroblasts. Odontol. Rev. 1969, 20, 427-436.

(C) 2018 by the authors. Licensee MDPI, Basel, Switzerland. This article is an open access article distributed under the terms and conditions of the Creative Commons Attribution (CC BY) license (http:/ / creativecommons.org/licenses/by/4.0/). 